\title{
Children and Youth Who Use Cannabis for Pain Relief: Benefits, Risks, and Perceptions
}

This article was published in the following Dove Press journal:

Adolescent Health, Medicine and Therapeutics

\author{
Julia J Woo' \\ Emma A van Reekum (iD) ${ }^{2}$ \\ Tea Rosic (D) ${ }^{3}$ \\ Zainab Samaan $\mathbb{D}^{3}$ \\ 'Faculty of Medicine, University of \\ Toronto, Toronto, ON, Canada; ${ }^{2}$ Faculty \\ of Medicine, McMaster University, \\ Hamilton, ON, Canada; ${ }^{3}$ Department of \\ Psychiatry and Behavioural \\ Neurosciences, McMaster University, \\ Hamilton, ON, Canada
}

\begin{abstract}
We provide up-to-date perspectives on the benefits and risks of medical cannabis for pain management in children and youth. To date, only two studies (a case report and a small observational study) have examined the effects of medical cannabis on pain in children and youth. No controlled trial has commented on long-term safety of medical cannabis. Findings from the recreational cannabis literature reveal significant potential short- and long-term risks of regular cannabis use, including impaired driving, depression, suicidality, psychosis, and tolerance. Despite this, many children and youth are selfmedicating with cannabis, and perceive regular cannabis use to be safe. There is a need for better education and counselling of patients regarding the benefits and risks of medical cannabis use.
\end{abstract}

Keywords: marijuana, THC, CBD, adolescents, pediatrics

\section{Introduction}

Cannabis is the most widely used illicit drug in the world. ${ }^{1}$ Its use is particularly common among children and adolescents. In the US, 37\% of 12th graders report using cannabis in the past year, ${ }^{2}$ with prevalence rising significantly among youth from $23.9 \%$ in 1991 to $35.6 \%$ in $2016 .{ }^{3}$ Similarly, one-third of Canadian youth have tried cannabis at least once by age $15 .^{1}$ The prevalence of cannabis use will likely continue to rise, in part due to recent waves of legalization. In the US, recreational cannabis has been legalized in 11 states, while 33 states allow for some form of legalized medical cannabis. ${ }^{4}$ Minors under the age of 18 are permitted to apply for medical cannabis cards, given that they have the permission of a physician as well as their guardian. ${ }^{4}$ Recreational cannabis was legalized in Canada in 2018. All Canadian provinces allow the prescription of medical cannabis. Although Health Canada warns against prescribing cannabis to those under age 25 , there is no absolute contraindication based on age; rather, physicians are asked to weigh the potential benefits and risks on a case-by-case basis. ${ }^{5}$

Cannabinoids act on two main receptors within the human endocannabinoid system: $\mathrm{CB}_{1}$ and $\mathrm{CB}_{2} . \mathrm{CB}_{1}$ is distributed throughout the central nervous system (CNS), with highest concentrations in the amygdala, hippocampus, basal ganglia, and prefrontal cortex. ${ }^{6}$ It plays a modulatory role in a wide range of critical processes such as nocioception, coordination, learning, rewards, appetite, anxiety, and mood. ${ }^{7} \mathrm{CB}_{2}$ receptors, in contrast, are expressed primarily in peripheral immune tissues. ${ }^{8}$ More recently, there has been evidence that a third cannabinoid receptor exists, with distinct signaling properties from $\mathrm{CB}_{1}$ and $\mathrm{CB}_{2}$, although its exact identity and function remain
Correspondence: Zainab Samaan St. Joseph's Healthcare Hamilton, West 5th Campus, 100 West 5th Street, Hamilton, ON L9C 0E3, Canada Tel +I-905-522-II $55 \times 39215$ Email samaanz@mcmaster.ca 
elusive. $^{9,10}$ Tetrahydrocannabinol (THC) and cannabidiol (CBD), in turn, are the two most studied cannabinoids. THC is the main psychoactive component and a partial $\mathrm{CB}_{1}$ and $\mathrm{CB}_{2}$ agonist. ${ }^{11}$ On the other hand, $\mathrm{CBD}$ has low affinity to $\mathrm{CB}_{1}$ and $\mathrm{CB}_{2}{ }^{12}$ and possesses anti-inflammatory and anti-spasmodic benefits without prominent psychoactive effects. ${ }^{13}$ There are two synthetic cannabinoids approved for medical use - dronabinol and nabilone - both of which are chemically similar to THC. ${ }^{14,15}$ More recently, plant-derived CBD has also been FDA-approved in the form of Epidiolex. Many cannabis products also contain varying concentrations of other bioactive ingredients such as terpenoids and flavonoids, which are beyond the scope of this paper; for more information regarding their properties and potential effects in pain, readers are encouraged to refer to reviews by Baron ${ }^{16}$ and Russo. $^{17}$

As cannabinoids are involved in such a wide array of CNS and immune processes, there has been growing interest in their use in medicine, particularly for pain management. While some evidence supports medical cannabis use in adults with neuropathic pain, ${ }^{18-20}$ less is known about the safety and efficacy of medical cannabis in pediatric patients. Therefore, in this paper we aimed to provide an overview of the efficacy and safety of medical cannabis for pain relief in children and youth. We discuss the prevalence and characteristics of medical cannabis use in this population, as well as its benefits and harms. Lastly, we discuss patients' and health-care providers' perception of medical cannabis, and provide recommendations for future research in this area.

\section{Methods}

We searched PubMed, PsychInfo, Web of Science, and CINAHL using the following search terms: ("cannabis" or "cannabinoid*" or "marijuana" or "CBD" or "THC") AND ("pediatric*" or "paediatric*" or "child" or "children" or "teen*" or "adolescent*" or "youth*" or "young adult*") AND pain. Article titles and abstracts were screened by three reviewers (JW, TR, and EVR). Articles were included if they studied one of the following: prevalence or characteristics of medical cannabis use; efficacy of medical cannabis for pain relief; short- or long-term risks of medical or recreational cannabis; and beliefs, attitudes, and perceptions of patients, families, and healthcare regarding medical cannabis. Only studies on children and youth (aged 24 and below) were included. NonEnglish articles were excluded.

\section{Prevalence and Characteristics of Medical Cannabis Use Among Children and Youth}

Estimates of the prevalence and patterns of pediatric medical cannabis use vary. A 2012-13 US survey of 4579 12th graders found medical cannabis use prevalence of $1.1 \% .^{21}$ Medical users accounted for 3\% of all youth who used cannabis in the past year. ${ }^{21}$ In Colorado and Washington, individuals under age 18 make up $0.39-1 \%$ of all patients with medical cannabis registration. ${ }^{22,23}$ On the other hand, in a study of 6509 students in California, 28\% of those who had used cannabis in the last 30 days held a medical cannabis card. $^{24}$

Seizures and severe pain are the most commonly reported reasons for using medical cannabis in children aged 0-10 and 11-17 years, respectively. ${ }^{22}$ There do not appear to be significant sociodemographic differences between youth who use cannabis medically and recreationally. ${ }^{25}$ However, medical cannabis patients are 1.6 times more likely to report pain conditions, 1.4 times more likely to report neurological conditions, and twice as likely to report mental health issues than young adults who use cannabis recreationally. ${ }^{25}$

With respect to characteristics of use, Tucker et al reported that among 671 adolescents aged 13-19 using cannabis in California, having a medical cannabis card was associated with greater quantity and frequency of use, as well as greater risk of cannabis-associated problems including: driving under the influence of cannabis (DUIC), missing school or work, and lower performance in school. ${ }^{24}$ Those with medical cannabis cards were also more likely to report having felt the need to cut down or quit cannabis in the last three months. ${ }^{24}$ Results remained consistent even after controlling for self-reported physical and mental health status. ${ }^{24}$ On the other hand, Fedorova et al found that medical cannabis use was negatively associated with illicit drug use in young adults aged $18-26 .^{26}$ This is consistent with findings from the adult literature that those who use cannabis medically are less likely to use illicit substances, ${ }^{27,28}$ and that some medical cannabis patients are utilizing cannabis as a substitute for other substances such as alcohol, opioids, and illicit drugs. ${ }^{29-31}$

\section{Self-Medicating with Cannabis}

Some studies show that children and youth describe using cannabis to self-medicate. In a survey of 169 young adults using cannabis, there were 41 mentions of self-medication for pain, 79 for anxiety, and 44 for depression. ${ }^{6,32}$ In a sample of young adult cannabis users with history of trauma, severity 
of PTSD symptoms was significantly associated with using cannabis for coping. ${ }^{33}$ Thus, the aforementioned epidemiological data may not capture a large number of children and youth self-medicating with cannabis.

\section{Efficacy of Medical Cannabis in Pain Management Among Children and Youth}

A recent systematic review identified just one study - a case report - on the efficacy of medical cannabis in pain management among children and youth. ${ }^{34}$ This report trialed dronabinol in two adolescents with chronic neuropathic pain and refractory major depressive disorder. ${ }^{34}$ The first participant reported $45 \%$ improvement in pain intensity, while the second reported no improvement. In both, four months of dronabinol was associated with $50 \%$ improvement in the affective component of pain, in that they found their pain to be less debilitating. Participants also perceived improvements in mood, sleep, activities of daily life, academic performance, and relationships. However, the perceived benefits of dronabinol gradually dissipated, leading to its discontinuation in 12 months at the patients' request. ${ }^{34}$

Similar, modest improvements in pain were found in a small, non-controlled study that examined CBD and THC in 25 patients aged 1-17 years with complex motor disorders. ${ }^{35}$ Two formulations of Avidekel whole plant CBDenriched 5\% oil extract were used: CBD-to-THC ratio 6:1 and CBD-to-THC ratio 20:1. ${ }^{35}$ After five months, participants reported a 1.41-point reduction in pain on a 10-point scale $(\mathrm{p}$ $=0.02) .{ }^{35}$ Statistically significant improvements were also seen in dystonia, spasticity, motor function, quality of life, mood, appetite, and sleep. ${ }^{35}$ Notably, the analyses were not adjusted for multiple comparison error, despite the study having included more than 36 comparisons.

More evidence exists for medical cannabis in adults. The 2017 National Academies of Sciences, Engineering, and Medicine (NASEM) report on cannabis found substantial evidence that cannabis is effective for chronic pain management among adults. ${ }^{36}$ Similarly, a review of trials on inhaled THC found a dose-dependent effect on neuropathic pain, with similar effect sizes (number needed to treat (NNT) 5.6 [95\% CI 3.4-14]) as gabapentin (NNT 5.9 $[95 \% \mathrm{CI} 4.6-8.3]) .^{20}$ No randomized-controlled trial to date has commented on long-term efficacy of medical cannabis (defined as longer than 26 weeks), and thus it is unclear whether these benefits persist over time. ${ }^{19}$ It is also unclear whether the benefits demonstrated in adult studies are generalizable to the youth population.

\section{Risks}

\section{Medical Cannabis Literature}

A systematic review of medical cannabis in children and adolescents found that the most common adverse effects of THC and CBD are drowsiness, dizziness, diarrhea, and increased appetite; all of which seem to improve with dose reduction. ${ }^{37}$ More recently, a small observational study of patients aged 1-17 years with complex motor disorders found that $\mathrm{CBD}$ and $\mathrm{THC}$ were associated with serious adverse events in five out of 25 participants, including behavioral change, somnolence, and worsening seizures. $^{35}$ All serious adverse events were reversible through dose reduction. ${ }^{35}$ In adults, a Cochrane systematic review on medical cannabis for neuropathic pain found greater prevalence of adverse CNS events (61\% vs $29 \%$; number needed to harm (NNTH) 3 [95\% CI 2-6]) and adverse psychiatric symptoms (17\% vs 5\%; NNTH 10 [95\% CI 7-16]) in the intervention group compared to placebo. ${ }^{19}$ Patients receiving medical cannabis were more likely to withdraw from studies due to adverse events compared to those receiving placebo $(10 \%$ vs $5 \%$; NNTH 25 [95\% CI 16-50]). ${ }^{19}$

Overall, no randomized-controlled trial in pediatric or adult populations has commented on long-term risks of medical cannabis. Two observational, open-label extension studies in adults found no increase in the frequency or severity of adverse effects over 32- and 38-week periods, respectively. ${ }^{38,39}$ Apart from one participant showing mild signs of dependence, there were no other reports of tolerance or abuse. ${ }^{38,39}$

\section{Recreational Cannabis Literature}

Due to the scarcity of evidence on the safety of medical cannabis in children and youth, we also outline findings from the literature on recreational cannabis.

\section{Cognition}

A meta-analysis of 69 studies on 2515 cannabis users and 6575 controls (mean age 20 years) found heavy or frequent cannabis use to be associated with lower performance in neurocognitive testing However, the effect size was small (mean $\mathrm{d}-0.25,95 \% \mathrm{CI}-0.32$ to -0.17 ) and transient; it became negligible when users abstained from cannabis for 72 hours (mean $\mathrm{d}-0.08,95 \% \mathrm{CI}-0.22$ to 0.07 ). ${ }^{40}$ 


\section{Driving}

Cannabis is the illicit drug most frequently implicated in impaired driving, and younger age is a risk factor for DUIC. $^{41}$ Four meta-analyses found DUIC to be linked with increased risk of motor vehicle collisions, although there was a wide range in the estimated effect sizes $(20-266 \%) .{ }^{42-45}$ There is a dose-dependent relationship between THC and the level of impairment on driving. ${ }^{46}$

\section{Mood and Anxiety}

In a meta-analysis of 11 studies on 23,317 adolescents, cannabis use during adolescence was associated with increased adulthood risk of depression (OR 1.37, 95\% CI 1.16-1.62), suicidal ideation (OR 1.50, 95\% CI 1.112.03), and suicidal attempt (OR 3.46, 95\% CI 1.53-7.84), but not with anxiety (OR $1.18,95 \%$ CI $0.84-1.67) .{ }^{47}$ These results were adjusted for age, sex, socioeconomic status, alcohol, smoking, and baseline anxiety or depression symptoms. $^{47}$

\section{Psychosis}

Cannabis users commonly experience acute, transient symptoms of psychosis such as paranoia and hallucinations. ${ }^{48}$ Recently there has been substantial evidence that cannabis use is also linked with development of psychotic disorders such as schizophrenia. ${ }^{36}$ A 2016 meta-analysis involving 10 studies and 66,816 participants found a dose-dependent relationship between cannabis use and risk of psychotic symptoms (OR 3.59, 95\% CI 2.42-5.32) as well as diagnoses of schizophrenia or other psychotic disorders (OR 5.07, 95\% CI 3.62-7.09). ${ }^{49}$ Participants with baseline psychotic symptoms were excluded from analyses. The analyses were not adjusted for confounders; however, two studies that did control for confounders (eg, ethnicity, sex, early emotional or behavioral problems, and use of other substances) confirmed this association. ${ }^{50,51}$ Interestingly, cannabis use is not associated with worsening of negative symptoms of schizophrenia. ${ }^{36}$

Despite these findings, it is difficult to draw a causal relationship between cannabis and psychosis; instead, the relationship between cannabis and psychotic disorders is likely multifactorial. In fact, substance use disorders and mental illness are generally considered to be risk factors for one another and share significant overlap in underlying neurochemical and neurobiological pathways. ${ }^{36,48}$ In particular, patients with schizophrenia often exhibit negative symptoms years prior to the onset of psychosis; thus, it's possible that early cannabis use history reflects selfmedication for prodromal symptoms of schizophrenia, as opposed to the underlying cause of schizophrenia. ${ }^{52}$ In addition, predisposing factors such as genetic and environmental vulnerabilities may place certain individuals at increased risk of both cannabis use and psychosis. ${ }^{36}$

\section{Tolerance and Other Drug Use}

A recent systematic review reported that repeated cannabis exposure leads to tolerance, with greatest tolerance to cognitive effects and partial tolerance to psychoactive and cardiac effects. ${ }^{53}$ Further, $8.9 \%$ of cannabis users eventually meet diagnostic criteria for cannabis use disorder, ${ }^{54}$ with greater risk $(17 \%)$ seen in those who started using before adulthood. ${ }^{55}$ There are also concerns that cannabis can lead to use of other substances, acting colloquially as a "gateway drug". The 2017 NASEM report found moderate-quality evidence of a link between cannabis use and increased risk of developing substance use disorder for other substances, including alcohol, tobacco, and illicit drugs. ${ }^{36}$ For instance, after adjusting for covariates (ex. early tobacco/ alcohol use, conduct disorder, depression, and social anxiety), one twin study found that those who used cannabis by age 17 were significantly more likely to develop alcohol (OR 1.85, 95\% CI 1.21-2.83), stimulant (OR 3.79, 95\% CI 1.60-9.01), or opioid (OR 5.00, 95\% 1.10-22.82) use disorder compared to their twin controls. ${ }^{56}$ Interestingly, early cannabis use was only marginally associated with increased risk of cannabis use disorder after adjusting for covariates (OR 1.57, 95\% 0.98-2.52). ${ }^{56}$

On the other hand, there is some evidence that cannabis use is associated with reduced use of other harmful substances. In a longitudinal study of street-involved youth, daily cannabis use was negatively associated with the use of IV stimulants. ${ }^{57}$ In a survey of 2032 Canadian medical cannabis users, $69 \%$ reported using cannabis as a substitute for prescription drugs (35\% of which were for opioids), $44 \%$ for alcohol, $31 \%$ for tobacco, and $27 \%$ for illicit substances. ${ }^{29}$ Of those who mentioned substituting for opioids, 59\% reported total cessation of opioid use after initiating medical cannabis. $^{29}$ At the population level, a 2014 study found $24.5 \%$ lower rates of opioid overdose mortality in states with medical cannabis laws compared to those without legalized medical cannabis $(95 \%$ CI $-37.5 \%$ to $-9.5 \%){ }^{31}$ However, when this analysis was extended through a longer period (up to 2017), the relationship between medical cannabis laws and opioid overdose appeared to reverse directions; states that legalized medical cannabis experienced a $22.7 \%$ increase in opioid overdose mortality rates $(95 \% \mathrm{CI}$ $2.0-47.6 \%){ }^{58}$ Most recently, a 2019 systematic review and 
meta-analysis of adults with opioid use disorder found no effect of cannabis use in opioid use. ${ }^{59}$ Therefore, findings on this topic continue to be too mixed and scarce to allow strong conclusions.

\section{Drug-Drug Interactions}

Antidepressants, antipsychotics, anticonvulsants, and proton pump inhibitors are some of the most commonly prescribed medications among children and youth (estimated prevalence of $1.2 \%, 0.9 \%, 0.8 \%$, and $0.6 \%$, respectively). ${ }^{60}$ They can also have significant drug-drug interactions with THC; co-administration with THC results in increased bioavailability and adverse effects of these medications. ${ }^{61}$ Moreover, fluoxetine - the most commonly used antidepressant in pediatrics ${ }^{60}$ - inhibits the metabolism of THC, thus resulting in increased risk and severity of the THC adverse effects mentioned previously. ${ }^{61}$ This is particularly concerning considering that a large number of children and youth may be self-medicating with cannabis without consulting a physician, thus increasing the risk of potential drug-drug interactions. So far, no data are available on what proportion of children and youth are reporting their cannabis use (either recreational or medical) to their health-care providers.

\section{Patient and Provider Perspectives of Medical Cannabis}

To date, two qualitative studies have explored children and youth's attitudes and beliefs about self-medicating with cannabis. ${ }^{62,63}$ The first study interviewed 20 individuals aged 13-18 in British Columbia, Canada who were using cannabis without prescription to manage various physical and mental health conditions. ${ }^{62}$ Five teens reported using cannabis for pain, including pain from muscle injury, burns, headaches, and menstruation. Participants frequently described cannabis as a "natural" product that is safer than conventional pharmacotherapy. Despite perceived benefits, participants were concerned over potential harm to their immune system, energy, memory, cognition, and school performance. Many teens consumed cannabis several times a day, with some using prior to school; these teens referred to cannabis as a "need" or an "addiction". Regardless, the majority were unconcerned with their use. ${ }^{62}$

Similar results were documented in a qualitative, Canadawide report of 77 youth aged $14-19 .{ }^{63}$ Positive effects on body and mind were one of the most frequently reported reasons for using cannabis. Adolescents described using cannabis to manage their stress, arthritis, pain, seizures, cancer, and mental illness. Many also perceived cannabis to be a healthier and more "natural" alternative to other medications. Youth acknowledged the potential for cannabis to harm their "brain cells" as well as motivation, memory, and mental health. Respondents suggested that better understanding of the risks of cannabis would not change their patterns of use. ${ }^{63}$

In terms of health-care provider perspectives, a study of 288 pediatric oncologists in the US showed that just 5\% of providers were aware of state-specific regulations pertaining to cannabis. ${ }^{64}$ However, $30 \%$ had received at least one request for medical cannabis in the past month, $26 \%$ of which were for pain. Only $8 \%$ reported ever suggesting medical cannabis to patients, and most felt that cannabis should be reserved for palliative or treatment-refractory cases only. Providers reported many barriers to authorizing medical cannabis, including the lack of familiarity around its dosing and safety. ${ }^{64}$

Similarly, several professional organizations such as the Canadian Psychiatric Association, ${ }^{65}$ American Academy of Pediatrics, ${ }^{66}$ and Canadian Pediatric Association, ${ }^{67}$ have all published official statements warning of the lack of data on efficacy and safety of medical cannabis in the pediatric population. The Canadian Pediatric Society stated that

"overall, there are insufficient data to support the efficacy or safety of cannabis use for any indications in children, and an increasing body of data suggests possible harm ... "68

and later urged policymakers and physicians to limit pediatric access to medical or recreational cannabis until further evidence becomes available. ${ }^{67}$

\section{Discussion and Conclusion}

Based on the current literature, there is insufficient evidence to support routine use of medical cannabis for pain in children and youth. The potential risks of cannabis are significant, compared to the sparse evidence for its benefits in pain management. To date, only two studies (a case report and a small observational study) have examined the effects of cannabis on pain in this population. ${ }^{34,35}$ Both studies were of poor quality, making it impossible to draw strong conclusions about efficacy. Known short-term adverse effects of medical cannabis are mostly mild, and can be managed through dose reduction. ${ }^{18,37}$ However, no controlled trial has commented on long-term safety of medical cannabis. ${ }^{35,37}$ Findings from recreational cannabis literature demonstrate significant shortand long-term harms, such as increased risk of lung cancer and COPD,${ }^{69}$ impaired driving, ${ }^{42-45}$ depression, ${ }^{47}$ suicidality, ${ }^{47}$ psychosis, ${ }^{49}$ and tolerance. ${ }^{53}$ 
The mechanisms of action behind most of these risks are poorly understood. One possibility is that those with an underlying genetic vulnerability are at greater risk of facing adverse effects of cannabis, such as psychosis. For instance, a post-mortem mRNA expression study found increased $\mathrm{CB}_{1}$ binding in the dorsolateral prefrontal cortex of patients with paranoid schizophrenia compared to controls. ${ }^{70}$ There is also some evidence that certain genetic polymorphisms (such as $A K T 1$ ) are implicated in the association between cannabis and psychosis. ${ }^{71}$

Interestingly, there is a discrepancy between patients' and providers' perceptions of medical cannabis. While clinicians are generally cautious of using cannabis for pain in this population, ${ }^{64-68}$ many children and youth are already selfmedicating with cannabis without guidance from health-care professionals. ${ }^{32,33,62,63}$ Studies have elucidated common misperceptions among youth, such as: cannabis is "natural" and thus safer than other forms of pharmacotherapy; cannabis is effective for pain control; and there are no serious harms associated with regular cannabis use. ${ }^{62,63}$ These results clearly indicate a need for better evidenced-based education about cannabis for children and youth.

One important caveat in interpreting this literature is that not all findings from studies of recreational cannabis may be applicable to medical cannabis. Patterns or frequency of use, doses, and concentrations of CBD and THC may vary between recreational and medical users. Moreover, while there is some evidence that cannabis is beneficial for neuropathic pain in adults, ${ }^{18,19}$ one cannot simply extrapolate these findings to children and youth. As previously mentioned, the endocannabinoid system is under active development during childhood and adolescence, and little is known about the longterm effects of cannabis exposure on the developing brain. Furthermore, certain adverse effects such as depression, psychosis, suicidal behavior, and poor school performance may be particularly detrimental to young people, given their potential to impact important long-term outcomes.

Furthermore, the literature on the prevalence and characteristics of medical cannabis use in children and youth continues to be scarce, with studies using widely different sampling methods and populations - making it challenging to draw any conclusions about the prevalence of and common indications for use. Similarly, there is limited research on patient and provider perspectives. The two studies that explored perspectives of children and youth were relatively small, qualitative studies. ${ }^{62,63}$ There was only one study that explored provider perspectives on this topic, and it used a highly specific sample of US pediatric oncologists. ${ }^{64}$ Both sets of studies make it difficult to draw population-wide generalizations about patient or provider perspectives.

Another major limitation in the literature is that no controlled trial has commented on efficacy or safety of medical cannabis in pain management beyond 26 weeks in pediatric or adult populations. While two open-label extension studies in adults reported continued pain improvement and no increase in adverse events after 32 and 38 weeks, ${ }^{38,39}$ these studies were at high risk of bias.

Lastly, it is difficult to draw generalizations across the wide range of existing cannabis products. Products vary greatly in terms of their concentrations of CBD and THC, ${ }^{72}$ which in turn have different mechanisms of action and psychoactive properties. Further, there is no standardized dosing or regimen for medical cannabis, making it even more challenging to draw conclusions from the literature or for providers to make evidenced-based suggestions for patients.

Going forward, well-designed randomized-controlled trials using standardized measures of pain are needed to establish the efficacy of medical cannabis in pain management among children and youth. Future studies should comment on both short- and long-term risks of medical cannabis, accounting for a variety of domains including medical, neuropsychiatric, cognitive, and social. With growing interest in this field, we also expect future studies to explore predictors of treatment benefit and adverse outcomes, which will in turn allow for more individualized clinical decision-making. Lastly, there is a need for further explorations of public perception of medical cannabis, to better understand the rationale for common misperceptions such as cannabis being "safer" and more "natural" than other medications. Elucidating patients' and families' beliefs, concerns, and needs will help guide future research and allow physicians to better counsel and educate patients on this issue.

\section{Disclosure}

Dr Zainab Samaan reports grants from CIHR during the conduct of the study. The authors report no other conflicts of interest in this work.

\section{References}

1. Currie C, Zanotti C, Morgan A, et al. Social Determinants of Health and Well-Being Among Young People. Health Behaviour in SchoolAged Children (HBSC) Study: International Report from the 2009/ 2010 Survey. World Health Organization; 2012.

2. Johnston L, Miech R, O'Malley PM, Bachman J, Schulenberg J, Patrick M. Monitoring the Future National Survey Results on Drug Use: 1975-2017: Overview, Key Findings on Adolescent Drug Use. Michigan: The University of Michigan Institute for Social Research; 2018. 
3. Miech R, Johnston L, O'Malley PM. Prevalence and attitudes regarding marijuana use among adolescents over the past decade. Pediatrics. 2017;140(6):e20170982. doi:10.1542/peds.2017-0982

4. State Medical Marijuana Laws. National conference of state legislatures; 2020. Available from: https://www.ncsl.org/research/ health/state-medical-marijuana-laws.aspx.

5. Health Canada. Information for Health Care Professionals: cannabis and the Cannabinoids. Government of Canada; 2018. Available from: https://www.canada.ca/en/health-canada/services/drugs-medication /cannabis/information-medical-practitioners/information-health-careprofessionals-cannabis-cannabinoids.html\#a5.0.

6. Katona I, Rancz EA, Acsády L, et al. Distribution of CB1 cannabinoid receptors in the amygdala and their role in the control of GABAergic transmission. $J$ Neurosci. 2001;21(23):9506-9518. doi:10.1523/JNEUROSCI.21-23-09506.2001

7. Lu H-C, Mackie K. An introduction to the endogenous cannabinoid system. Biol Psychiatry. 2016;79(7):516-525. doi:10.1016/j. biopsych.2015.07.028

8. Schatz AR, Lee M, Condie RB, Pulaski JT, Kaminski NE. Cannabinoid receptors $\mathrm{CB} 1$ and $\mathrm{CB} 2$ : a characterization of expression and adenylate cyclase modulation within the immune system. Toxicol Appl Pharmacol. 1997;142(2):278-287. doi:10.1006/ taap.1996.8034

9. Lauckner JE, Jensen JB, Chen H-Y, Lu H-C, Hille B, Mackie K. GPR55 is a cannabinoid receptor that increases intracellular calcium and inhibits M current. Proc Natl Acad Sci U S A. 2008;105 (7):2699-2704. doi:10.1073/pnas.0711278105

10. Fride E, Foox A, Rosenberg E, et al. Milk intake and survival in newborn cannabinoid $\mathrm{CB} 1$ receptor knockout mice: evidence for a "CB3" receptor. Eur J Pharmacol. 2003;461(1):27-34. doi:10.101 6/s0014-2999(03)01295-0

11. Pertwee RG. The diverse CB1 and CB2 receptor pharmacology of three plant cannabinoids: delta9-tetrahydrocannabinol, cannabidiol and delta9-tetrahydrocannabivarin. $\mathrm{Br} \quad J$ Pharmacol. 2008;153 (2):199-215. doi:10.1038/sj.bjp.0707442

12. Thomas A, Baillie GL, Phillips AM, Razdan RK, Ross RA, Pertwee RG. Cannabidiol displays unexpectedly high potency as an antagonist of $\mathrm{CB} 1$ and $\mathrm{CB} 2$ receptor agonists in vitro. $\mathrm{Br}$ J Pharmacol. 2007;150(5):613-623. doi:10.1038/sj.bjp.0707133

13. Pisanti S, Malfitano AM, Ciaglia E, et al. Cannabidiol: state of the art and new challenges for therapeutic applications. Pharmacol Ther. 2017;175:133-150. doi:10.1016/j.pharmthera.2017.02.041

14. FDA Information. Marinol (Dronabinol). High Point, North Carolina: Solvay Pharmaceuticals; 2004. Available from: https://www.access data.fda.gov/drugsatfda docs/label/2005/018651s021lbl.pdf.

15. FDA Information. Cesamet (Nabilone). Costa Mesa, California: Valeant Pharmaceuticals International; 2006. Available from: https://www. accessdata.fda.gov/drugsatfda_docs/label/2006/018677s011lbl.pdf.

16. Baron EP. Medicinal properties of cannabinoids, terpenes, and flavonoids in cannabis, and benefits in migraine, headache, and pain: an update on current evidence and cannabis science. Headache. 2018;58 (7):1139-1186. doi:10.1111/head.13345

17. Russo EB. Taming THC: potential cannabis synergy and phytocannabinoid-terpenoid entourage effects. $\mathrm{Br} \mathrm{J}$ Pharmacol. 2011;163(7):1344-1364. doi:10.1111/j.1476-5381.2011.01238.x

18. Whiting PF, Wolff RF, Deshpande S, et al. Cannabinoids for medical use: a systematic review and meta-analysis. JAMA. 2015;313 (24):2456-2473. doi:10.1001/jama.2015.6358

19. Mücke M, Phillips T, Radbruch L, Petzke F, Häuser W. Cannabisbased medicines for chronic neuropathic pain in adults. Cochrane Database Syst Rev. 2018;3:CD012182. doi:10.1002/14651858. CD012182.pub2

20. Andreae MH, Carter GM, Shaparin N, et al. Inhaled cannabis for chronic neuropathic pain: a meta-analysis of individual patient data J Pain. 2015;16(12):1221-1232. doi:10.1016/j.jpain.2015.07.009
21. Boyd CJ, Veliz PT, McCabe SE. Adolescents' use of medical marijuana: a secondary analysis of monitoring the future data. $J$ Adolesc Health. 2015;57(2):241-244. doi:10.1016/j.jadohealth.2015.04.008

22. Medical marijuana statistics and data. Colorado Department of Public Health and Environment; February 2020. Available from: https:// www.colorado.gov/pacific/cdphe/medical-marijuana-statistics-anddata. Accessed April 7, 2020.

23. Washington State Department of Health. Medical marijuana data and statistics; April 25, 2019. Available from: https://www.doh.wa.gov/ Youand YourFamily/Marijuana/MedicalMarijuana/ AuthorizationDatabase/DataandStatistics. Accessed June 15, 2019..

24. Tucker JS, Rodriguez A, Pedersen ER, Seelam R, Shih RA, D'Amico EJ. Greater risk for frequent marijuana use and problems among young adult marijuana users with a medical marijuana card. Drug Alcohol Depend. 2019;194:178-183. doi:10.1016/j. drugalcdep.2018.09.028

25. Lankenau SE, Ataiants J, Mohanty S, Schrager S, Iverson E, Wong CF. Health conditions and motivations for marijuana use among young adult medical marijuana patients and non-patient marijuana users. Drug Alcohol Rev. 2018;37(2):237-246. doi:10.1111/ dar. 12534

26. Fedorova EV, Schrager SM, Robinson LF, et al. Illicit drug use and prescription drug misuse among young adult medical cannabis patients and non-patient users in Los Angeles. Drug Alcohol Depend. 2019;198:21-27. doi:10.1016/j.drugalcdep.2019.01.026

27. Lin LA, Ilgen MA, Jannausch M, Bohnert KM. Comparing adults who use cannabis medically with those who use recreationally: results from a national sample. Addict Behav. 2016;61:99-103. doi:10.1016/j.addbeh.2016.05.015

28. Wall MM, Liu J, Hasin DS, Blanco C, Olfson M. Use of marijuana exclusively for medical purposes. Drug Alcohol Depend. 2019;195:13-15. doi:10.1016/j.drugalcdep.2018.11.009

29. Lucas P, Baron EP, Jikomes N. Medical cannabis patterns of use and substitution for opioids \& other pharmaceutical drugs, alcohol, tobacco, and illicit substances; results from a cross-sectional survey of authorized patients. Harm Reduct J. 2019;16(1):9. doi:10.1186/ s12954-019-0278-6

30. Reiman A. Cannabis as a substitute for alcohol and other drugs. Harm Reduct J. 2009;6(1):35. doi:10.1186/1477-7517-6-35

31. Bachhuber MA, Saloner B, Cunningham CO, Barry CL. Medical cannabis laws and opioid analgesic overdose mortality in the United States, 1999-2010. JAMA Intern Med. 2014;174 (10):1668-1673. doi:10.1001/jamainternmed.2014.4005

32. Osborn LA, Lauritsen KJ, Cross N, et al. Self-medication of somatic and psychiatric conditions using botanical marijuana. $J$ Psychoactive Drugs. 2015;47(5):345-350. doi:10.1080/02791072.2015.1096433

33. Bonn-Miller MO, Vujanovic AA, Feldner MT, Bernstein A, Zvolensky MJ. Posttraumatic stress symptom severity predicts marijuana use coping motives among traumatic event-exposed marijuana users. J Trauma Stress. 2007;20(4):577-586. doi:10.1002/jts.20243

34. Rudich Z, Stinson J, Jeavons M, Brown SC. Treatment of chronic intractable neuropathic pain with dronabinol: case report of two adolescents. Pain Res Manag. 2003;8(4):221-224. doi:10.1155/ 2003/675976

35. Libzon S, Schleider -LB-L, Saban N, et al. Medical cannabis for pediatric moderate to severe complex motor disorders. $J$ Child Neurol. 2018;33(9):565-571. doi:10.1177/0883073818773028

36. National Academies of Sciences, Engineering, and Medicine, Health and Medicine Division, Board on Population Health and Public Health Practice, Committee on the Health Effects of Marijuana: An Evidence Review and Research Agenda. The Health Effects of Cannabis and Cannabinoids: The Current State of Evidence and Recommendations for Research. Washington (DC): National Academies Press (US); 2017. Available from: http://www.ncbi.nlm. nih.gov/books/NBK423845/.Accessed April 9, 2020. 
37. Wong SS, Wilens TE. Medical cannabinoids in children and adolescents: a systematic review. Pediatrics. 2017;140(5). doi:10.1542/peds.20171818

38. Schimrigk S, Marziniak M, Neubauer C, Kugler EM, Werner G, Abramov-Sommariva D. Dronabinol is a safe long-term treatment option for neuropathic pain patients. Eur Neurol. 2017;78(5-6):320-329. doi:10.1159/000481089

39. Hoggart B, Ratcliffe S, Ehler E, et al. A multicentre, open-label, follow-on study to assess the long-term maintenance of effect, tolerance and safety of THC/CBD oromucosal spray in the management of neuropathic pain. J Neurol. 2015;262(1):27-40. doi:10.1007/s00415-014-7502-9

40. Scott JC, Slomiak ST, Jones JD, Rosen AFG, Moore TM, Gur RC. Association of cannabis with cognitive functioning in adolescents and young adults: a systematic review and meta-analysis. JAMA Psychiatry. 2018;75(6):585-595. doi:10.1001/jamapsychiatry.2018.0335

41. Robertson RD, Mainegra Hing M, Pashley CR, Brown SW, Vanlaar WGM. Prevalence and trends of drugged driving in Canada. Accid Anal Prev. 2017;99(Pt A):236-241. doi:10.1016/j.aap.2016.12.008

42. Elvik R. Risk of road accident associated with the use of drugs: a systematic review and meta-analysis of evidence from epidemiological studies. Accid Anal Prev. 2013;60:254-267. doi:10.1016/j. aap.2012.06.017

43. Rogeberg O, Elvik R. The effects of cannabis intoxication on motor vehicle collision revisited and revised. Addict Abingdon Engl. 2016;111(8):1348-1359. doi:10.1111/add.13347

44. Asbridge M, Hayden JA, Cartwright JL. Acute cannabis consumption and motor vehicle collision risk: systematic review of observational studies and meta-analysis. BMJ. 2012;344:e536. doi:10.1136/bmj.e536

45. Li M-C, Brady JE, DiMaggio CJ, Lusardi AR, Tzong KY, Li G. Marijuana use and motor vehicle crashes. Epidemiol Rev. 2012;34 (1):65-72. doi:10.1093/epirev/mxr017

46. Lenné MG, Dietze PM, Triggs TJ, Walmsley S, Murphy B, Redman JR. The effects of cannabis and alcohol on simulated arterial driving: influences of driving experience and task demand. Accid Anal Prev. 2010;42(3):859-866. doi:10.1016/j.aap.2009.04.021

47. Gobbi G, Atkin T, Zytynski T, et al. Association of cannabis use in adolescence and risk of depression, anxiety, and suicidality in young adulthood: a systematic review and meta-analysis. JAMA Psychiatry. 2019. doi:10.1001/jamapsychiatry.2018.4500

48. Radhakrishnan R, Wilkinson ST, D'Souza DC. Gone to Pot A review of the association between cannabis and psychosis. Front Psychiatry. 2014;5. doi:10.3389/fpsyt.2014.00054

49. Marconi A, Di Forti M, Lewis CM, Murray RM, Vassos E. Metaanalysis of the association between the level of cannabis use and risk of Psychosis. Schizophr Bull. 2016;42(5):1262-1269. doi:10.1093/ schbul/sbw003

50. Di Forti M, Morgan C, Dazzan P, et al. High-potency cannabis and the risk of psychosis. Br J Psychiatry J Ment Sci. 2009;195 (6):488-491. doi:10.1192/bjp.bp.109.064220

51. Miettunen J, Törmänen S, Murray GK, et al. Association of cannabis use with prodromal symptoms of psychosis in adolescence. Br J Psychiatry J Ment Sci. 2008;192(6):470-471. doi:10.1192/bjp.bp.107.045740

52. Manseau MW, Goff DC. Cannabinoids and schizophrenia: risks and therapeutic potential. Neurotherapeutics. 2015;12(4):816-824. doi:10.1007/s13311-015-0382-6

53. Colizzi M, Bhattacharyya S. Cannabis use and the development of tolerance: a systematic review of human evidence. Neurosci Biobehav Rev. 2018;93:1-25. doi:10.1016/j.neubiorev.2018.07.014

54. Lopez-Quintero C, Pérez de Los Cobos J, Hasin DS, et al. Probability and predictors of transition from first use to dependence on nicotine, alcohol, cannabis, and cocaine: results of the National Epidemiologic Survey on Alcohol and Related Conditions (NESARC). Drug Alcohol Depend. 2011;115(1-2):120-130. doi:10.1016/j.drugalcdep.2010.11.004
55. Volkow ND, Baler RD, Compton WM, Weiss SRB. Adverse health effects of marijuana use. $N$ Engl J Med. 2014;370(23):2219-2227. doi:10.1056/NEJMra1402309

56. Lynskey MT, Heath AC, Bucholz KK, et al. Escalation of drug use in early-onset cannabis users vs co-twin controls. JAMA. 2003;289 (4):427-433. doi:10.1001/jama.289.4.427

57. Reddon H, DeBeck K, Socias ME, et al. Cannabis use is associated with lower rates of initiation of injection drug use among street-involved youth: a longitudinal analysis. Drug Alcohol Rev. 2018;37(3):421-428. doi:10.1111/dar.12667

58. Shover CL, Davis CS, Gordon SC, Humphreys K. Association between medical cannabis laws and opioid overdose mortality has reversed over time. Proc Natl Acad Sci. 2019;116(26):12624-12626. doi:10.1073/pnas.1903434116

59. McBrien H, Luo C, Sanger N, et al. Cannabis use during methadone maintenance treatment for opioid use disorder: a systematic review and meta-analysis. CMAJ Open. 2019;7(4):E665-E673. doi:10.9778/ cmajo.20190026

60. Qato DM, Alexander GC, Guadamuz JS, Lindau ST. Prescription medication use among children and adolescents in the United States. Pediatrics. 2018;142(3):e20181042. doi:10.1542/peds.20181042

61. Brown JD. Potential adverse drug events with tetrahydrocannabinol (THC) due to drug-drug interactions. J Clin Med. 2020;9(4):919. doi: $10.3390 /$ jcm 9040919

62. Bottorff JL, Johnson JL, Moffat BM, Mulvogue T. Relief-oriented use of marijuana by teens. Subst Abuse Treat Prev Policy. 2009;4 (1):7. doi:10.1186/1747-597X-4-7

63. McKiernan A, Fleming K. Canadian Youth Perceptions on Cannabis. Ottawa, Ontario: Canadian Centre on Substance Abuse; 2017.

64. Ananth P, Ma C, Al-Sayegh H, et al. Provider perspectives on use of medical marijuana in children with cancer. Pediatrics. 2018;141(1): e20170559. doi:10.1542/peds.2017-0559

65. Tibbo P, Crocker CE, Lam RW, Meyer J, Sareen J, Aitchison K. Implications of Cannabis Legalization on Youth and Young Adults. Canadian Psychiatric Association; 2017.

66. Ammerman S, Ryan S, Adelman WP, Committee on Substance Abuse, the Committee on Adolescence. The impact of marijuana policies on youth: clinical, research, and legal update. Pediatrics. 2015;135(3):e769-e785. doi:10.1542/peds.2014-4147

67. Grant CN, Richard EB, Canadian Paediatric Society. Cannabis and Canada's children and youth. Paediatr Child Health. 2017;22 (2):98-102. doi: $10.1093 / \mathrm{pch} / \mathrm{pxx} 017$

68. Rieder MJ. Is the medical use of cannabis a therapeutic option for children? Paediatr Child Health. 2016;21(1):31-34. doi:10.1093/pch/ 21.1.31

69. Martinasek MP, McGrogan JB, Maysonet A. A systematic review of the respiratory effects of inhalational marijuana. Respir Care. 2016;61(11):1543-1551. doi:10.4187/respcare.04846

70. Dalton VS, Long LE, Weickert CS, Zavitsanou K. Paranoid schizophrenia is characterized by increased CB1 receptor binding in the dorsolateral prefrontal cortex. Neuropsychopharmacology. 2011;36 (8):1620-1630. doi:10.1038/npp.2011.43

71. Benyamina A, Karila L, Lafaye G, Blecha L. Genetic influences in cannabis use disorder and psychosis: dopamine and beyond. Curr Pharm Des. 2016;22(42):6392-6396. doi:10.2174/1381612822666 160831095707

72. Vergara D, Bidwell LC, Gaudino R, et al. Compromised external validity: federally produced cannabis does not reflect legal markets. Sci Rep. 2017;7:46528. doi:10.1038/srep46528 


\section{Publish your work in this journal}

Adolescent Health, Medicine and Therapeutics is an international, peer-reviewed, open access journal focusing on health, pathology, and treatment issues specific to the adolescent age group. All aspects of health maintenance, preventative measures and disease treatment interventions are addressed within the journal and practitioners from all disciplines are invited to submit their work as well as healthcare researchers and patient support groups. The manuscript management system is completely online and includes a very quick and fair peerreview system. Visit http://www.dovepress.com/testimonials.php to read real quotes from published authors. 